\title{
A PRECOLLEGE ENGINEERING AND SCIENCE SUMMER PROGRAM
}

\author{
Edward S. Pierson, Nancy L. Johnson \\ Purdue University Calumet
}

\section{Introduction}

The Calumet region (East Chicago, Gary, Hammond, and neighboring parts of Northwest Indiana and Illinois) has a very large minority student population with a low rate of enrollment in post-secondary education. The objective of this program, started in 1991, is to demonstrate to these students that there are excellent job opportunities in engineering and science where graduates can earn a good living while doing work they enjoy with interesting people. The focus is on a five-week summer program for students entering grades 8 or 9 , with follow-up activities for two succeeding summers (funds permitting). The key feature is the structure, which ties science, math, and applications together; thus topics are chosen so that the participants see the importance of math as a basic tool, and its application to engineering and science. The mornings are primarily lecture/discussion/demonstration; the afternoons are hands on sessions (laboratory and computer) or industrial tours. This is an enrichment program, not a remedial program.

\section{Need}

The program was started because, in spite of large number of minority and economically disadvantaged students in the communities surrounding Purdue Calumet, very few minorities were enrolled as engineering students at Purdue Calumet.

The statistical profile of East Chicago, Gary, and Hammond, Table 1, provides an excellent view of the problems. The college attendance rates are below the Indiana average, which is itself low. In every category the target communities score poorly -- look at percentages with bachelors degrees, families below poverty, single parent families, and percent of students eligible for free lunch. Note also the high percentage of minority students. Not shown are such problems as crime and environmental contamination, major issues for these old industrial cities which had major heavy industrial and petroleum firms; these make the communities unpleasant and drive upper-income residents to move elsewhere. Also, these firms are now ailing and reducing employment, have been taken over or merged, or are even out of business.

Considerable data is available on scholastic performance. SAT test scores are consistently lower than the Indiana average, which is itself low compared to national averages (see Table 1). Of particular significance is the percent of students scoring above the minimum math and English standards, and that is less than half the state average. Note also the low adult educational levels, indicating a lack of role models for the students. Finally, the graduation rates (see Table 2) are poor; Hammond and East Chicago are among the bottom ten in Indiana. 
Table 1. Statistical Profile of Target Area ${ }^{1}$

\begin{tabular}{|l|c|c|c|c|}
\hline & $\begin{array}{c}\text { School City of } \\
\text { East Chicago }\end{array}$ & $\begin{array}{c}\text { Gary Comm } \\
\text { School. Corp. }\end{array}$ & $\begin{array}{c}\text { School City of } \\
\text { Hammond }\end{array}$ & $\begin{array}{c}\text { Indiana } \\
\text { Averages }\end{array}$ \\
\hline $\begin{array}{l}\text { College Attendance } \\
\text { Rate, Class of 1996-97 }\end{array}$ & $47 \%$ & $52 \%$ & $53 \%$ & $60 \%$ \\
\hline $\begin{array}{l}\text { SAT Scores (Compos- } \\
\text { ite) 1996-97 }\end{array}$ & 783 & 793 & 931 & 991 \\
\hline $\begin{array}{l}\text { Pct 12th Graders } \\
\text { Taking SAT 1997 }\end{array}$ & $35 \%$ & $45 \%$ & $33 \%$ & $52 \%$ \\
\hline $\begin{array}{l}\text { Pct Above Math \& English } \\
\text { Standards 1997-98 }\end{array}$ & $23 \%$ & $26 \%$ & $38 \%$ & $55 \%$ \\
\hline $\begin{array}{l}\text { Adults with Less Than } \\
\text { High School Ed. 1990 }\end{array}$ & $39.9 \%$ & $32.9 \%$ & $29.5 \%$ & $23.4 \%$ \\
\hline $\begin{array}{l}\text { Pct of Adults with Bach- } \\
\text { elors Degree or Higher }\end{array}$ & $6.7 \%$ & $8.6 \%$ & $9.1 \%$ & \\
\hline $\begin{array}{l}\text { Pct Families Below } \\
\text { Poverty 1990 }\end{array}$ & $34.4 \%$ & $36.7 \%$ & $19.4 \%$ & $11.8 \%$ \\
\hline $\begin{array}{l}\text { Pct Single Parent } \\
\text { Families 1990 }\end{array}$ & $50.5 \%$ & $55.5 \%$ & $32.2 \%$ & $24.3 \%$ \\
\hline $\begin{array}{l}\text { Pct (gr. 1-12) Eligible for } \\
\text { Free Lunch 1997-98 }\end{array}$ & $71 \%$ & $57 \%$ & $48 \%$ & $22 \%$ \\
\hline $\begin{array}{l}\text { Pct Minority Students } \\
1997-98\end{array}$ & $95.5 \%$ & $91.1 \%$ & $43.3 \%$ & $15.6 \%$ \\
\hline Enrollment 1997-98 & 6,152 & 20,983 & 1,3984 & 3,368 \\
\hline
\end{tabular}

Table 2. State Ranking of School Corporations According to Graduation Rate ${ }^{1}$

\begin{tabular}{|l|c|c|}
\hline & State Ranking (out of 292) & \% Graduated \\
\hline Gary Community School Corp. & 184 & 88.3 \\
School City of Hammond & 287 & 69.5 \\
School City of East Chicago & 288 & 66.7 \\
\hline
\end{tabular}

\section{Goals}

The goals of this program are:

1. To excite students about careers in engineering and science by introducing a few ideas that can be understood by interested students with a seventh-grade education. Concepts not usually covered in high school are chosen.

2. To have the students meet and interact with engineers and scientists, especially those employed in local companies.

3. To involve parents in the process, thus providing home support.

4. To provide students with success-oriented (Positive Mental Attitude) training.

5. To have students experience the importance of working in teams. 
6. To involve precollege math and science teachers, and counselors, as learners, rather than teachers. This allows them to take ideas from this program to their classrooms, thus enabling more precollege students to learn from this program. In particular, the teachers and counselors will be more knowledgeable about engineering careers.

7. To provide students with additional program activities for two subsequent summers, funds permitting.

\section{Participant Recruitment and Selection}

Program announcements and applications are distributed in late spring to all middle-school or junior-high-school principals, counselors, and math/science teachers in East Chicago, Gary, and Hammond by means of individually-addressed envelopes; and to middle-school principles in the rest of Northwest Indiana. In addition, former participants and their parents are asked to spread the word about the program. (Word of mouth is an excellent source following nine summers of accomplishment; many siblings and relatives have participated. Each spring many requests for information are received.)

Candidates apply by means of an application form accompanied by a written statement of why they are interested in this program along with a summary of their school and community activities. Two recommendations are required -- from a counselor (accompanied by grades and standardized test scores), and from a science teacher. An effort is made to select both students who perform well, and underachievers who a teacher or counselor thinks will be motivated by the experience.

Students completing seventh or eighth grade are chosen because the beginning of their highschool education is the most-important time to influence high school courses and activities, and thus the career options that are available. Delayed course- and career-related decisions may result in extensive remediation, and in delays in admission to the desired postsecondary program. Starting the participants on the desired path early means college-preparatory math and science from the beginning of high school, and this makes it easier to maintain them on course.

\section{Schedule and Activities}

First-summer enrollment is limited to two groups of approximately 24 students each. Those students who have successfully completed one summer are invited to return for two more summers of different activities, funds permitting. The five-week summer session focuses on hands-on engineering and science applications, with supporting lectures, math foundations, and Positive Mental Attitude (PMA) sessions. The time structure for each day is:

\begin{tabular}{|c|c|c|}
\hline & GROUP A & GROUP B \\
\hline 8:30 am & \multicolumn{2}{|c|}{ Plans for day } \\
\hline $8: 40 \mathrm{am}$ & Math & Science \\
\hline 10:00 am & Science & Math \\
\hline 11:10 am & \multicolumn{2}{|c|}{ Lunch (staggered) \& group activity } \\
\hline $12: 40 \mathrm{pm}$ & Laboratory & Computers \\
\hline $2: 00 \mathrm{pm}$ & Computers & Laboratory \\
\hline $3: 10 \mathrm{pm}$ & \multicolumn{2}{|c|}{ Daily journals } \\
\hline $3: 30 \mathrm{pm}$ & \multicolumn{2}{|c|}{ Depart for home } \\
\hline
\end{tabular}


Visits to local industrial firms where participants observe engineers/ scientists at work, and see the application of the ideas learned, will replace some sessions. Some sessions are double length to allow the time needed for experiments.

Significant components of the program are described below. The topics for a typical summer are listed in Appendix 1; a few are explained in detail in following sections. The topics may change from year to year, depending on the availability and interests of teachers. Teachers may be engineering or science faculty, university staff, visitors from industry, or college students.

Method: The student activities were developed by specialists to emphasize their areas of interest. These activities generally include laboratory and computer sessions, and design competitions (fun activities that introduce engineering decision making based on cost, environment, reliability, etc.). Each topic, to the extent possible, is treated as follows:

1. The scientific background and the basics are introduced (e.g., DC electric circuits, see Section 7). To the extent possible, this should be student exploration. This may demonstrate the need for new mathematical tools.

2. The appropriate math (simultaneous linear equations) is taught to support the topic and to demonstrate the value of math. As appropriate, the math may be taught first.

3. Hands-on laboratory experience (electrical circuits lab) reinforce and apply the concepts while making the material more exciting and relevant; the students are active participants.

4. Computer applications (circuit analysis using Pspice or Electronic Workbench) demonstrate the use of a personal computer as a hands-on tool, often with specialized software, to further reinforce the material.

5. For some topics, a plant visit demonstrates the application within industry (electric utility distribution system). Site visits showcase the work of engineers and scientists, and the practical results of their efforts. Field trips make the learning process fun and relevant, and introduce potential career fields.

Math, science, and engineering are tied together in this fashion. Thus students see the value of math as a tool for science and engineering, as well as experience the excitement of discovery. Some of the activities are pieces of topics normally covered in college but not part of the normal high-school curriculum. Examples are in the following sections.

Laboratory: Hands-on laboratory experience is important, especially for younger students, to hold interest and to make concepts 'come alive.' Thus students experience the excitement of discovery. The lab work is in teams so students learn to work together.

Computers: Students use a personal computer (PC) and specialized software to support laboratory and analysis work, to plot experimental data, to write lab reports, etc. Students work individually or in pairs, as is educationally appropriate. Special PC facilities designed for teaching with computers are used.

Design Competitions: Design competitions are fun activities that introduce engineering decision making based on cost, environment, reliability, etc. In the first summer several construction projects introduce engineering concepts, including economics, see Section 8 . The first summer concludes with the egg drop contest -- each participant designs, builds, and tests a small 
cardboard container to protect an egg dropped from a third-floor roof. The winner is the participant whose egg survives in the lightest-weight (most-economical) container. The secondand third-summer participants do more advanced projects (see Appendix 1). Many projects are team activities, to reinforce that engineers and scientists work as members of a team. Trophies are awarded in all contests at the concluding Banquet to Celebrate Excellence.

Take Homes or Souvenirs: Each participant receives books and other material to support the concepts taught. The first-summer participants receive a scientific calculator so that all participants have the same model for teaching purposes. The participants build items to keep, such as the 'happy face' and the battery tester circuits that the first-summer students assemble from Graymark International ${ }^{2}$ kits. (These are small electronic kits that the students assemble, including soldering components onto a small printed circuit board. It is intellectually trivial, but the students really enjoy it and have the satisfaction of making something that works. Extra experienced help and troubleshooting is needed so that all students succeed.) Participants (as well as teachers and sponsors) receive a T-shirt designed by one of the participants in a contest; sponsors are acknowledged on the back. (The designs have been creative, better than the staff did in the years before the participant contest.) Group photos as well as candid shots of the activities are distributed. All of these are reminders of the program that also serve to attract future participants.

Positive Mental Attitude: Weekly sessions provide a success-oriented basis for the students' future. The first-summer focus is on self esteem; the second on conflict resolution, working in teams, and cooperative learning; and the third on careers. Self-esteem is so important because it gives participants confidence in themselves and their abilities. This component helps the participants to feel good about themselves, and to be more effective and productive. They are to be proud of their accomplishments, act independently, and assume responsibility. Participants with a good sense of self-esteem are more likely to be successful in school and in personal relationships.

Tours: There are two types of tours. First, company visits demonstrate the concepts taught. Examples include:

- the BP-Amoco Oil Company Whiting Refinery (chemistry and water treatment tied to the microbiology and chemistry class material, and refinery processes using plant lab facilities for third-year participants),

- a structure under construction (tied to construction),

- Lansing or Gary Airport (tied to airplane design),

- Ipsat-Inland or LTV Steel (steel production tied to materials properties), and

- Northern Indiana Public Service Company (electric power generation and distribution tied to electric circuits, and a power plant tied to thermodynamics and to motors and generators for second-year participants).

Second, students visit science-related museums, such as the Adler Planetarium, the Museum of Science and Industry, and/or the Shedd Aquarium.

Team Structure: To emphasize the importance of interpersonal skills and the improved output achieved when people combine their talents and strengths, as well as to introduce a skill required in the world of work, the team format was introduced in 1995. In the first week, the group 
leaders divide the students into three-person teams. With some modification to the team member roles as described in A Handbook on Cooperative Learning ${ }^{3}$, each student is assigned specific responsibilities within the team, Appendix 2. The roles may be rotated. This team structure ensures that all students participate in activities, and increases organization both in and out of the classroom. Field trips are easier, and instructors have noted the improved student focus and the overall increased organization.

Discipline: At the initial orientation session with parents (see parents below) a code of behavior is distributed, discussed, and signed by both the participant and a parent. This provides a clear understanding of the expected learning and behavior. Participants must not do anything that interferes with the learning of others, and in addition must be active participants in all aspects of the learning process. Students with unacceptable behavior, as identified by the teachers or the college student group leaders, are taken through a series of steps including 1) A meeting with the Director, 2) A letter to the parents, 3) A meeting with the parents, and 4) Dismissal from the program and notification of the participant's school. This last step is not to be taken lightly because it represents failure with this participant, but it is necessary that this option be available.

Writing: The program emphasizes writing as a skill required for all engineers and scientists. The last period of each day is devoted to the participants' writing in their daily journals.

Group Activity: The individual group leaders have a (lighter) session with their participants to break up the day. Examples are a visit to the gym, a game or contest with a science orientation, and a brief educational activity following up on a class session.

Banquet to Celebrate Excellence: The culminating event is the evening banquet for participants, parents and siblings, teachers, local school representatives, and sponsors and supporters. The focus is on the participants; there is no guest speaker. The program includes speeches from representative participants (selected by the participants and the college student group leaders) describing their experiences, impressions, and future plans; and former participants describing the impact of the program and their subsequent successes. The program concludes with the presentation of trophies and awards, and the presentation of certificates and T-shirts to all participants.

Training for Teachers: There are two very different types of teacher training. First, the Purdue Calumet faculty may not have experience with pre-college students, and the industrial personnel may not have taught at all. Since the instruction must involve the students and hold their attention, all instructors are expected to attend a training session.

Second, precollege science and math teachers are invited to learn and take ideas back to their classrooms (see the fifth goal above). This becomes an enrichment and sabbatical-type experience for these teachers, as well as a way to reach more precollege students. The added adults are also of value in guiding and disciplining the students. The teachers receive 3 hours of college credit, useful for maintaining certification. Based on experience, these teachers will come only if paid.

Parents: Parents (or guardians) are critical to this program's success; they must support and encourage their children to complete this program, and to obtain the education needed for 
admission to and success in a college math, engineering, or science program. There are three activities:

1. A required orientation session with parents and children before the program begins. Two alternative times -- Saturday morning or Wednesday evening -- are provided. Any family that does not participate is dropped from the program.

2. A required session for parents only in the middle of the program to demonstrate what the students are learning. The major focus is on career and college guidance. Again, two alternative times are provided. Non-participating parents pay for their banquet dinners.

3. A highly successful concluding Banquet to Celebrate Excellence described above.

\section{Staff}

The program is guided by a steering committee composed of the Program Director, the Assistant Director, one representative each from the East Chicago, Gary, and Hammond schools, one representative from each organization supporting the program, and one representative from participating Purdue Calumet departments.

The modules that make up the program are taught by Purdue Calumet faculty and staff, and by engineers and scientists from local companies who volunteer their time and expertise. The use of practicing engineers and scientists is emphasized so that the students see the excitement of these career fields. (This also makes scheduling challenging as teacher schedule changes often force last-minute program changes. It is recommended that extra topics like math games be available for emergencies.) These practitioners make the classes more relevant and also reduce the cost. Teachers are drawn from a large pool; each year approximately 60 teachers and industrial tour guides participate.

A college engineering student leads and mentors each group. Each student remains continuously with one group of participants through all activities, including lunch. Their functions include taking the participants to and from activities, assisting the teachers (especially for the lab and computer sessions), providing continuity for the participants, introducing the participants to college through informal contacts, and serving as role models. At their request, they have done some teaching and developed projects. Most of these students have been from Purdue Calumet, but recently some have been former participants, a plus because they are excellent role models and they know the program. The engineering students are chosen for their ability to relate to the participants, they receive two weeks of training. This use of engineering students has been extremely successful -- the students have developed close friendships, guided by example, and kept everything under control and moving smoothly. Many of these students have returned for subsequent summers.

Also, each summer one or two former participants who have completed three summers but not entered college are hired to provide assistance to the staff. They are extremely helpful, as well as examples of success for the current participants.

\section{Example -- Electric Circuits}

As an example of the approach described above, consider electric circuits. The first-year students study dc circuits, and the second-year students study ac circuits (requires more advanced 
math tools). In both cases, the basic concepts are introduced in lecture/discussion sessions taught by an engineering faculty member. As the need for mathematical tools is demonstrated, the math teachers teach the necessary math. Hands-on laboratory sessions reinforce the concepts by allowing the participants to build and test appropriate electrical circuits. At the same time they learn to use modern electrical test equipment -- multimeters, power supplies, oscilloscopes, etc. In companion computer sessions, specialized software (Pspice or Electronic Workbench) is used to model electrical circuits, and the results of the computer models are compared with the results from the lab experiments. The application of the concepts is demonstrated by a trip to the local electric utility, Northern Indiana Public Service Company, where participants visit engineering offices and the electric distribution center.

On a practical note, in 1991 when the program began, the students would sit for over an hour to hear a lecture on electric circuits. However, recently, the students would not sit and listen for extended periods of time - a more-active approach was needed. Thus, the structure outlined below has been used, with each session consisting of a 10-15 minute talk, with demonstrations, followed by a hands-on lab session, with the students working in pairs. A cart with a power supply, voltmeter and ammeter (both digital and analog to see the advantages and disadvantages of both), components, etc., is used for the demonstrations.

Session 1: Power supplies, voltmeters and ammeters

Session 2: Voltage-current for a resistor, Ohm's Law (plot)

Session 3: Ohm's Law, V-I for a light bulb (plot)

Session 4: Resistor color codes, resistors in series

Session 5/6 (double length): Resistors in parallel, Kirchoff's voltage and current laws

Session 7: Circuit analysis using Electronic Workbench - Kirchoff's voltage law

Session 8: Complex circuits - discussion and experiment

Session 9: Complex circuit using Electronic Workbench

Plant Visit (double length): Visit to NIPSCO (the local electric and gas utility, as well as a program sponsor), usually both the electrical distribution center and the engineering offices

The two Electronic Workbench sessions repeat on the PC previously-done experiments.

\section{Example -- Construction}

Construction is normally the first major topic covered -- it does not require much math background, it is easily grasped by the students, and there is much hands-on activity. The book The Art of Construction ${ }^{4}$ by Mario Salvadori is used as a resource, and each student receives a copy. The typical sessions are:

Session 1: Lecture-discussion on architects, engineers, history, and materials

Session 2: Lecture-discussion on loading, steel frames, beams, foundations, stress and strain

Sessions 3/4(double length): Surveying, with field experience. This can go anyplace in the schedule, but it must be preceded by two sessions on trig (used for this and the rockets, see Section 9). 
Sessions 5/6(double length): Build paper structures. Students build beams, arches, and structures; and test for weight-holding capability. This includes a three-span beam bridge built by teams in a contest. The bridges are evaluated on beauty (architecture) and cost (so much cost for each piece of paper, etc.), and prizes are awarded.

Sessions 7/8(double length): Build bridges with tongue depressors and brass paper fasteners; test bridges for weight and weight-holding capability (the ratio is the critical result).

Visit (double length): Visit a building or bridge under construction, in cooperation with Powers and Sons Construction, a local minority-owned company and program sponsor.

This is a popular topic, and involves several design contests. Activity sheets have been developed to guide the students.

Companion topics have been added in some years, depending on time and the availability of interested teachers. These include beams (modulus of elasticity and cantilever beam experiments) and materials (melting point of tin and breaking steel experiments, as well as a visit to a steel plant). A steel plant visit dramatizes the difference between the engineers in airconditioned offices and the workers in the hot, dirty plant.

\section{Example -- Rockets}

Rockets are introduced as a combination of theory and experiment. The first day consists of (along with other material) a lecture on rocket principles (forces governing flight, types), and a session on rocket trajectory simulations using a simple computer code to observe the influence of wind, thrust, and drag. On the second day each student spends a half day building a rocket kit from Estes ${ }^{5}$ (Alpha III or similar). Then the students take the rockets home for two days to decorate them. The morning of launch day contains a session on launch procedures and safety. Each student gets to push the button for his/her rocket, but staff inserts the engines and connects the wires. The students also take turns measuring the (four) angles and retrieving the rockets. (We plan a rain day and pray for good weather.) The day after the launch, a session is spent using triangulation to calculate the heights. Trophies are given for the highest rocket and the best design. Problems that occur include a few students leaving their rockets home or damaging them, and inaccurate angle measurements that put the calculations in question. However, this is an informative and fun project.

\section{Example -- Trig for Rockets and Surveying}

Often the mathematics content for the program is dictated by the choice of engineering/science topics. Two such examples are surveying and determining rocket heights. While students come to the program with differing levels of math proficiency, almost none have studied trigonometry. (This is not unexpected since the participants are entering grades 8 or 9.) The initial trig session begins with a discussion of the Pythagorean Theorem for right triangles, a topic that fortunately is familiar to many of the students. The trigonometric ratios for sine, cosine, and tangent are then established, and students work in teams to solve right triangles with some sides or angles unknown. Solutions requiring the use of the inverse trig functions to find an angle measure prove especially difficult and are not emphasized due to time constraints; however, the more advanced students grasp the inverse concept. 
The second session, usually scheduled for the following day, allows the students to apply what they have learned. The math instructor poses the problem of finding the height of the room without directly measuring it. A corner of the room where two side walls meet serves as the "vertical leg" of a right triangle since the walls are (hopefully) perpendicular to the floor. The other leg of the right triangle is the distance from the corner to any pre-chosen point on the floor and is measured by footsteps, which are then converted to inches or decimal feet. The angle of elevation is determined by a homemade measuring instrument consisting of a drinking straw affixed to the straight side of a protractor with a washer suspended on a thread which aligns with the angle markings on the protractor as the elevation angle increases. The resulting tangent equation is solved using a scientific calculator and the height of the classroom is found. Next teams of students move outdoors to measure the height of various trees and buildings. Since actual confirmation of the true heights is not possible, at least two teams are assigned to the same structure to allow for comparison of results. Students enjoy this activity, and anticipate putting their understanding to use with the upcoming launch of their rockets, as well as the surveying session.

Since the rocket launch is held on the soccer field, students have trouble visualizing triangles some of whose sides exist in vertical space. For this reason the use of a model, complete with string showing the sides of the airborne triangles, helps students determine which angles and distances must be measured and recorded. Participants take turns measuring angles of elevation and ground angles from two different vantage points as each rocket is launched. Calculations for rocket height are performed during a subsequent classroom session. Since the ground triangle is not a right triangle, it is necessary to introduce the Law of Sines. A guided worksheet leads the students through the triangulation process with the average of the heights of two vertical triangles serving as the final rocket height.

From a mathematical perspective, the rocket activity proves to be a rich environment for investigation and application. Working primarily in a team format makes the somewhat challenging trigonometry manageable and fun while the rocket launch itself results in fierce competition for most successful individual launch as judged by greatest height. When these students encounter trigonometry in their future high school course work, they will have a sound base for further study.

\section{Results to Date}

An important measure of success is the high percentage of participants who return for subsequent summers. The recent results are:

$\begin{array}{lllllll} & 1994 & 1995 & 1996 & 1997 & 1998 & 1999 \\ \text { Returning for a second summer: } & 71 \% & 78 \% & 75 \% & 70 \% & 53 \% & 75 \% \\ \text { Returning for a third summer: } & 85 \% & 80 \% & 79 \% & & & \end{array}$

The return rates were high until 1997 when financial problems caused uncertainty about the existence of the second-summer program and canceled the third-summer program. In particular, in 1998 the availability of the second-summer program was announced in early June after previously telling participants it would be cancelled, it was only two weeks long, and it coincided with weeks four and five of the first-summer program. 
The evaluations on the exit surveys at the end of each summer are quite positive. This feedback implies that the program is working well; it also provides guidance for future improvements. Table 3 shows the participant feedback for first-year students on the components that make up the program. Most topics were perceived as being well taught and worthwhile.

The degree of goal achievement is another measure of success. The evaluations from the parents and the participants are shown separately in Tables 4 and 5, respectively.

Perhaps the best measure of success is the college attendance of former participants. For the 49 participants who started in summer 1993, 35 returned for a second summer and 28 returned for a third summer. Of the 49, 43 were located in the summer of 1998 . Of these 43, 40 were currently in college with one additional student having started in engineering but dropped out. Of the 40 in college, 11 were majoring in engineering, 8 in science, and a total of 26 in math/science related fields. An additional 4 were undecided or unknown majors. In interpreting these results, note that the program was supported that summer in part by the National Science Foundation through its Summer Science Camps program for under-represented minorities, and all but one of the participants were from East Chicago and Gary. The number of engineering/math/science majors is extremely high, providing evidence that the program is working.

For the 50 participants who started in summer 1994, again all under-represented minorities, 37 returned for a second summer and 31 for a third summer. In 199940 were located; the stated majors are 12 in engineering, 3 in science, 4 in premed or pharmacy, and 3 in computers. Again, over half are in math/science related fields.

\section{Summary}

The Engineering and Science Summer Program has operated successfully for nine years. Approximately 423 students and 28 precollege teachers have participated, many (both students and teachers) for more than one summer. Financial support is an ongoing problem; lack of funds has severely crippled the program for the last three summers. Most important, the evaluations and college attendance data demonstrate that the program is meeting its goals.

Acknowledgement

Support for the program has been provided by Allied Signal; Ameritech; Association of Iron \& Steel Engineers - Chicago Chapter; Bank One; Bethlehem Steel Foundation; BP Amoco Foundation and Whiting Refinery; City of Gary; Department of Energy, Office of Energy Research, through its Division of University and Industry Programs; Gary Community School Corporation; Indiana Space Grant Consortium; Ipsat-Inland Steel, Inc.; LTV Steel; Lucent Technologies; National Science Foundation; Northern Indiana Public Service Company; Northwest Indiana Business Roundtable; Powers and Sons Construction Company, Inc.; Purdue University Calumet; Rhodia, Inc.; Safety-Kleen Oil Recovery Co.; School City of East Chicago; Superior Engineering Corporation; Twin City Education Foundation; United States Steel Gary Works; and WMX Technologies, Inc.

Bibliography

1. Indiana Dept. of Education Website, 1998. URL: http://ideanet.doe.state.in.us.

2. Graymark International, Inc., P.O. Box 2015, Tustin, CA, 92681, 800-854-7393. 
3. Duncan-Hewitt, W., Mount, D. and Apple, D., A Handbook on Cooperative Learning, .First Edition, copyright W. Duncan-Hewitt, Faculty of Pharmacy, University of Toronto.

4. Salvadori, M., The Art of Construction. Chicago, IL: Chicago Review Press (1990). Also Salvadori Educational Center on the Built Environment, City College of New York, Harris Hall - Room 202, Convent Avenue at $138^{\text {th }}$ Street, New York, NY 10031, 212-650-5497.

5. Estes Industries, 1295 H. Street, Penrose, CO 81240, 800-820-0202.

\section{EDWARD S. PIERSON}

Edward S. Pierson is the creator and director of the Engineering and Science Summer Program. He is Special Assistant to the Chancellor for Environmental Affairs and a Professor of Electrical Engineering, and was head of the Department of Engineering, all at Purdue University Calumet. He has worked on advanced energy systems for many years. He has a B.S. degree from Syracuse University, and S.M. and Sc.D. degrees from MIT, all in electrical engineering.

\section{NANCY LEHR JOHNSON}

Nancy Lehr Johnson is an Assistant Professor of Mathematics at Purdue University Calumet. She received her B.S. in Mathematics at Illinois State University in 1969 and her M.S. in Mathematics from Purdue Calumet in 1972. She has been assistant director of the Engineering and Science Summer Program since its inception, and created the math component. Her interests include working with pre-service teachers at both the elementary and secondary levels. She also serves as the undergraduate advisor for the Department of Mathematics, Computer Science, and Statistics 
Table 3 - Evaluation of Components, 1999 First-Summer Participants

Subject Areas

Math

Biology

Chemistry

Construction

PC usage

Build happy face $\&$ battery checker

Materials

Positive Mental Attitude (PMA)

DC electric circuits

Digital logic

Statistical process control

AutoCAD

Air quality

\begin{tabular}{l}
\multicolumn{2}{c}{ Evaluation (\%) } \\
Poor Fair Good Gery
\end{tabular}

Tours

Construction site (Powers and Sons)

Museum of Science and Industry

Ipsat-Inland Steel

NIPSCO (local electric/gas utility)

Safety Kleen (chemistry)

$\begin{array}{rrrrr}7 & 14 & 14 & 30 & 32 \\ 7 & 16 & 25 & 18 & 30 \\ 2 & 20 & 20 & 27 & 25 \\ 9 & 14 & 23 & 27 & 32 \\ 0 & 11 & 14 & 16 & 55 \\ 0 & 0 & 9 & 25 & 64 \\ 2 & 25 & 11 & 18 & 39 \\ 5 & 5 & 14 & 20 & 55 \\ 16 & 27 & 14 & 11 & 25 \\ 2 & 16 & 27 & 25 & 25 \\ 9 & 14 & 11 & 27 & 32 \\ 0 & 2 & 9 & 18 & 66 \\ 2 & 14 & 18 & 32 & 30\end{array}$

General

Engineering Projects

$\begin{array}{llrrrr}\text { Paper Arch } & 2 & 5 & 9 & 11 & 66 \\ \text { Bridge (wood) } & 2 & 2 & 14 & 9 & 68 \\ \text { Rocket } & 0 & 2 & 9 & 7 & 75 \\ \text { Egg Drop } & 7 & 5 & 9 & 7 & 68 \\ \text { Helpfulness in making college choices } & 9 & 14 & 14 & 20 & 39 \\ \text { Helpfulness in making career choices } & 9 & 14 & 16 & 23 & 32 \\ \text { Food } & 2 & 14 & 20 & 18 & 39 \\ \text { Transportation } & 7 & 7 & 23 & 18 & 36 \\ \text { Banquet } & 0 & 5 & 5 & 20 & 61\end{array}$

Note: The values in the table are the percentages for those students who answered the question.

Some students did not answer every question. 
Table 4 - Achievement of Goals, 1999 First-Summer Parents

Degree of Achievement (number)

Goal

$\begin{array}{ccc}\text { Not } & \text { A } & \\ \text { at All } & \underline{\text { Little }} & \text { Partly }\end{array}$

To identify career opportunities

in engineering and science

0

$\begin{array}{lll}0 & 11 & 31\end{array}$

To more clearly identify personal attitudes and feelings toward engineering and science

$\begin{array}{llll}0 & 2 & 8 & 32 \\ 0 & 0 & 3 & 39 \\ 1 & 2 & 9 & 30 \\ 0 & 0 & 7 & 33 \\ 3 & 5 & 9 & 24 \\ 2 & 1 & 6 & 33\end{array}$

Table 5 - Achievement of Goals, 1999 First-Summer Participants

To learn more about how math, science, and engineering interact

To get a better idea of what career might be best for your child

To understand the opportunities

in engineering and science

To understand the opportunities in particular for women in engineering and science

To understand the opportunities in particular for minorities in engineering and science

Degree of Achievement (\%)

Goal

To identify career opportunities in engineering and science

$\begin{array}{ccc}\text { Not } & \text { A } & \\ \text { at All Little } & \text { Partly Fully }\end{array}$

To more clearly identify personal attitudes and feelings toward engineering and science

To learn more about how math, science, and engineering interact

To get a better idea of what career might be best for you

$\begin{array}{llll}0 & 0 & 60 & 40\end{array}$

$\begin{array}{llll}0 & 23 & 38 & 38\end{array}$

$\begin{array}{llll}0 & 15 & 33 & 52\end{array}$

To understand the opportunities in engineering and science

To understand the opportunities in particular for women in engineering and science

To understand the opportunities in particular for minorities in engineering and science

$\begin{array}{llll}0 & 14 & 29 & 57\end{array}$

$\begin{array}{llll}0 & 4 & 62 & 35\end{array}$

Note: The values in the table are percentages of those who completed the survey. Some students did not answer every question. 


\section{APPENDIX 1}

\section{TYPICAL SUMMER ACTIVITY SUMMARY}

\author{
FIRST SUMMER \\ Subject Areas \\ AutoCAD \\ Beams \\ Biology \\ Build happy face \& battery \\ checker electronic kits \\ Chemistry \\ Construction \\ DC electric circuits \\ Digital logic \\ Engineering projects \\ Paper arch \\ Bridge (wood, paper) \\ Rocket \\ Egg drop \\ Material properties \\ Mathematics \\ Personal computers \\ Positive Mental Attitude \\ Statistical process control \\ Tours \\ Amoco Whiting Refinery (tie \\ to chemistry \& biology) \\ Museum of Science \& \\ Industry, Chicago \\ NIPSCO engineering center \\ (electric/gas utility) (tie to \\ circuits) \\ Ipsat-Inland Steel (tie to \\ materials) \\ Powers \& Sons (tie to \\ construction) \\ General \\ Career guidance and college \\ prep \\ Banquet to Celebrate \\ Excellence
}

$\underline{\text { SECOND SUMMER }}$

Subject Areas

AC electric circuits

Airplanes made from file folders

Diodes, rectifiers, \& transistors

Engineering projects Airplanes

Mousetrap springpowered cars

Mathematics

Microcomputers applied to control

Motors \& generators

Personal computers

Positive Mental Attitude

Programmable logic controllers

Project management

Science Olympiad

Thermodynamics and steam power

Tours

Lansing Airport (tie to airplanes)

Adler Planetarium and Shedd Aquarium, Chicago

NIPSCO power plant (electric/gas utility) (tie to motors \& generators, \& thermodynamics)

\section{General}

Banquet to Celebrate Excellence

\section{THIRD SUMMER}

Subject Areas

Electronics project (pair project)

Fluid mechanics

How it works (pair project)

Lotus applied to engineering problems

Oil refinery processes, taught at Amoco Whiting Refinery

Positive Mental Attitude

Quick Basic - using it to write computer games

Telephone systems

Tours

Ameritech (tie to telephone systems)

Amoco Whiting Refinery (tie to oil refinery processes)

Museum of Science \& Industry, Chicago

General

Banquet to Celebrate Excellence 


\section{APPENDIX 2}

\section{TEAM ROLES AND RESPONSIBILITIES}

\section{Leader}

1. Oversees team work, makes sure members stay on task and carry out their roles and responsibilities.

2. Takes over for absent team member or designates a substitute. Keeps copy of any handouts for absent team member.

3. Keeps team together in designated areas.

4. Designates/rotates team spokesperson.

5. Reports absences and distributes tickets as requested by group leader.

Recorder/Materials Person

1. Maintains all notes and data for the team.

2. Is responsible for assembling and keeping track of the team's solutions/work on handouts.

3. Hands in team assignments.

4. Is responsible for obtaining and returning team materials.

Reflector/Technology Person

1. Works equipment/calculator/computer.

2. Summarizes work/activity done by team.

3. States the goal of the work/activity.

4. Gives insight into what was learned and includes how results were affected by changing variables. Gives suggestions for further exploration.

5. Writes brief (half page) reflector's report that addresses the above objectives. This report will be shared with team members for their feedback and possible corrections or additions. A sample reflector's report is given below.

Sample reflector's report

Today our team constructed a model paper airplane. We had various designs to choose from. Our team chose the X-wing fighter. On flight trials, this model proved to give the longest flight distance, but it flew at very low altitudes. Next time we will adjust the position of the weights to try and increase the altitude. Our leader did a good job of keeping us focused, but we wasted time decorating our plane.

When an activity requires students to work in pairs rather than teams of three, the reflectors from two teams will pair up, thereby forming three teams of two each. 